\title{
Sediment-water oxygen and nutrient fluxes in a hypoxic estuary
}

\author{
M. Nørlem ${ }^{\text {a,b }}$, D. Paraska ${ }^{\text {a }}$ and M. R. Hipsey ${ }^{\text {a }}$ \\ ${ }^{a}$ School of Earth and Environment, University of Western Australia 35 Stirling Highway, Crawley, Western \\ Australia, 6009 \\ ${ }^{b}$ Aalborg University, Fredrik Bajers Vej 5, P.O. Box 159, Denmark, 9100 \\ Email: parasd02@student.uwa.edu.au
}

\begin{abstract}
Examining sediment-water fluxes can be essential for understanding aquatic chemistry and ecosystems, but the numerous coupled processes near the sediment-water interface make this a difficult system to analyse. This is especially pertinent in periodically hypoxic, nutrient-rich waterways, where the sediment oxygen demand and rates of sediment nutrient flux interact with the water column chemistry and ecology. In this paper, a region of the seasonally-hypoxic Swan River estuary in Perth, Western Australia, is examined to determine nutrient fluxes and the effect of oscillating bottom water oxygen conditions. The oxygen fluctuations investigated are designed to capture variability on seasonal scales as well as with high frequency (daily) changes in water column oxygen concentrations due to pumping by an oxygenation plant.
\end{abstract}

A numerical sediment diagenesis model is used to examine the system under natural and pumping conditions. The model is validated against available datasets of porewater depth profiles and fluxes of $\mathrm{NH}_{4}{ }^{+}, \mathrm{NO}_{3}{ }^{-}$and dissolved inorganic carbon. The simulated flux of $\mathrm{NH}_{4}{ }^{+}$is found to be $16.3 \mathrm{mmol} \mathrm{N} \mathrm{d}$. The peak flux of $\mathrm{PO}_{4}{ }^{3-}$ corresponds to the period of anoxia. The depth of oxygen penetration into the sediment is between 1 and $1.5 \mathrm{~mm}$, which shows little variation between oxic and anoxic bottom water conditions. It was found that there was limited time lag between the bottom water oxygen concentration and the sediment porewater concentration and therefore the sediment oxygen demand was largely insensitive to antecedent conditions. The model was used to develop a simple oxygen flux relationship for use in water quality models of the area. Areas for improvement of the model include the need for refining the timescale of oxygen fluctuation to capture the effects of changes shorter than one day; specifying separate organic matter rate constants for different reaction pathways; changing the effects of bioturbation and bioirrigation to reflect hypoxic environments; and including the effects of feedbacks into the water column, which can next be achieved by coupling this sediment model with a pelagic hydrodynamic and ecosystem model.

Keywords: $\quad$ Dynamic sediment diagenesis model, hypoxia, Swan River Estuary, oxygenation 


\section{INTRODUCTION}

Examining the chemistry at the sediment-water interface can be essential to understanding many aquatic systems. The upper layers of the sediment contain processes of organic matter oxidation and preservation, oxygen consumption and nutrient cycling. These processes in isolation and the feedbacks between them can be difficult to unravel in hypoxic, nutrient-rich sites, especially when algal blooms consume nutrients and produce oxygen and labile organic matter, which, upon degradation in the sediment, consumes oxygen and can lead to an increased nutrient release. A valuable tool for calculating the balance of these processes is the early diagenesis model, which has been used to examine many hypoxic, nutrient-rich environments such as estuaries and coastal lagoons (Eldridge and Morse 2000, Eldridge et al. 2004).

These processes are examined for the Swan River Estuary in Perth, Western Australia. The Swan receives its highest rainfall in winter and very little in summer, when a hypoxic, density-stratified "salt wedge" pushes upstream. Hypoxia has been exacerbated by increased inputs of nutrients and organic matter over many decades and has led to the destruction of benthic fauna habitat and mass fish kills. To alleviate this problem, oxygenation plants have been established at the most affected sites. The oxygenation plant has been shown to increase the oxygen penetration depth into the sediment under continuous 10-day operation. In this period the oxygen level was measured daily and showed a gradual increase in oxygen concentration until a stretch of 4.3 $\mathrm{km}$ showed concentrations near or above saturation (Kilminster et al. 2011). However, the operational costs of the plant are high and the strategy is currently to oxygenate the water only during night time to reduce power expenses. Oxygen concentrations fluctuate on a daily cycle, with the frequency of the tides, and also over seasonal time scales. Therefore the purpose of this study is to examine the flux and reaction of nutrients and oxygen, and the depth of oxygen penetration into the sediment.

\section{MODEL SETUP AND VALIDATION}

The Computational Aquatic Ecosystem Dynamics Model (CAEDYM) applies a finite-difference scheme to solve the 1D depth resolved transport-reaction equations governing the sediment processes (termed diagenesis) and is a modification of the early diagenesis model CANDI (Carbon and Nutrient Diagenesis) described by Boudreau (1996) and the subsequent revision C.CANDI (Calcite, Carbon and Nutrient Diagenesis) presented in Luff et al. (2000). The chemical reactions included in the model are given in Table 1. The sediment was simulated to a depth of $30 \mathrm{~cm}$, divided into 65 grid cells with the distance between the centre nodes increasing with depth.

Sediment chemical depth profiles and fluxes were sourced from extensive surveys of the hypoxic salt wedge region around Guildford, Perth, by Fredericks et al. (2002), Smith et al. (2006) and Smith and Evans (2010). An annual averaged boundary condition was used for all considered species and calibrated towards the spatial and time-averaged depth profiles and benthic flux measurements. As such the aim of the model setup was to yield an "average" steady-state representation of the upper estuary sediments. The most extensive datasets were found for porewater concentrations of $\mathrm{NH}_{4}{ }^{+,} \mathrm{PO}_{4}{ }^{3-}$ and dissolved inorganic carbon (DIC) and therefore the primary target for calibration was to reproduce concentration depth profiles of these three species, while still having a reasonable agreement with other species that have been measured less frequently (Figure 1). Benthic nutrient flux data was used to validate the model after calibration towards the measured sediment depth profiles. The median fluxes of $\mathrm{NH}_{4}{ }^{+}, \mathrm{NO}_{3}{ }^{-}$and $\mathrm{PO}_{4}{ }^{3-}$ were $7.85 \mathrm{mmol} \mathrm{N} \mathrm{m} \mathrm{d}^{-1},-0.02 \mathrm{mmol}$ $\mathrm{N} \mathrm{m}^{-2} \mathrm{~d}^{-1}$ and $0.68 \mathrm{mmol} \mathrm{P} \mathrm{m} \mathrm{m}^{-2}$. The model was spun up under an asymptotic run over 7 years, until the changes in $\mathrm{NH}_{4}{ }^{+}$and $\mathrm{PO}_{4}{ }^{3-}$ were less than $1 \%$, under the constant boundary conditions given in Table 2

Table 1 Reactions included in the CAEDYM diagenesis model

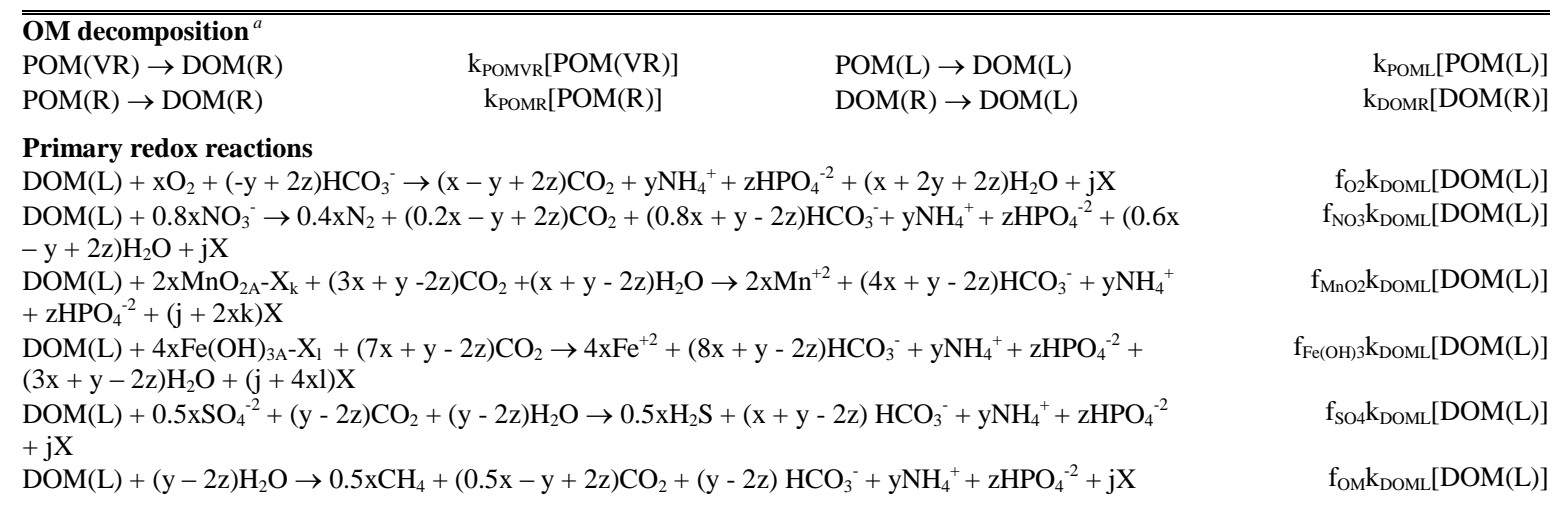




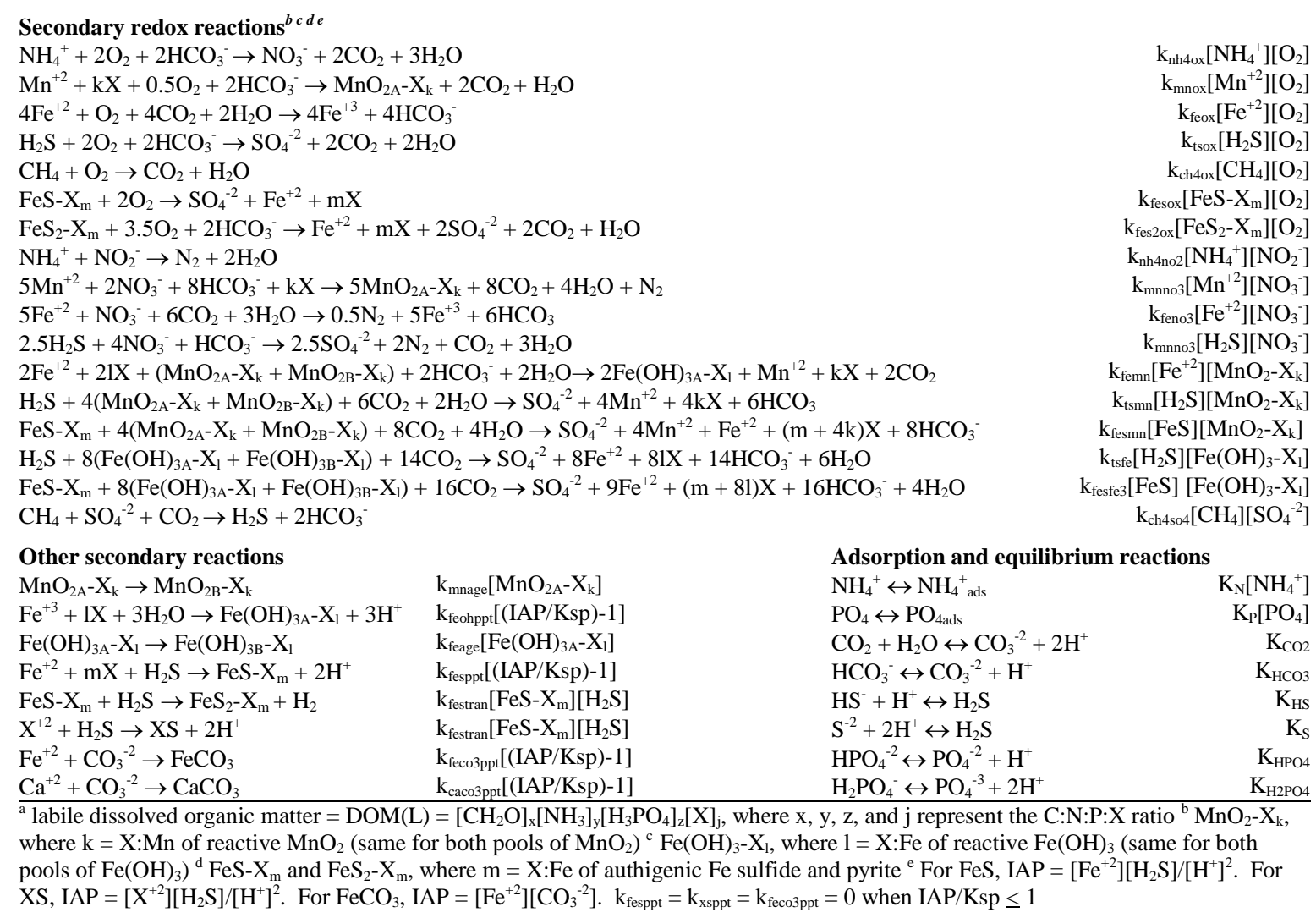

Table 2 Boundary conditions in this simulation, giving the upper boundary (UBC), fixed concentration (FC) or fixed flux (FF)

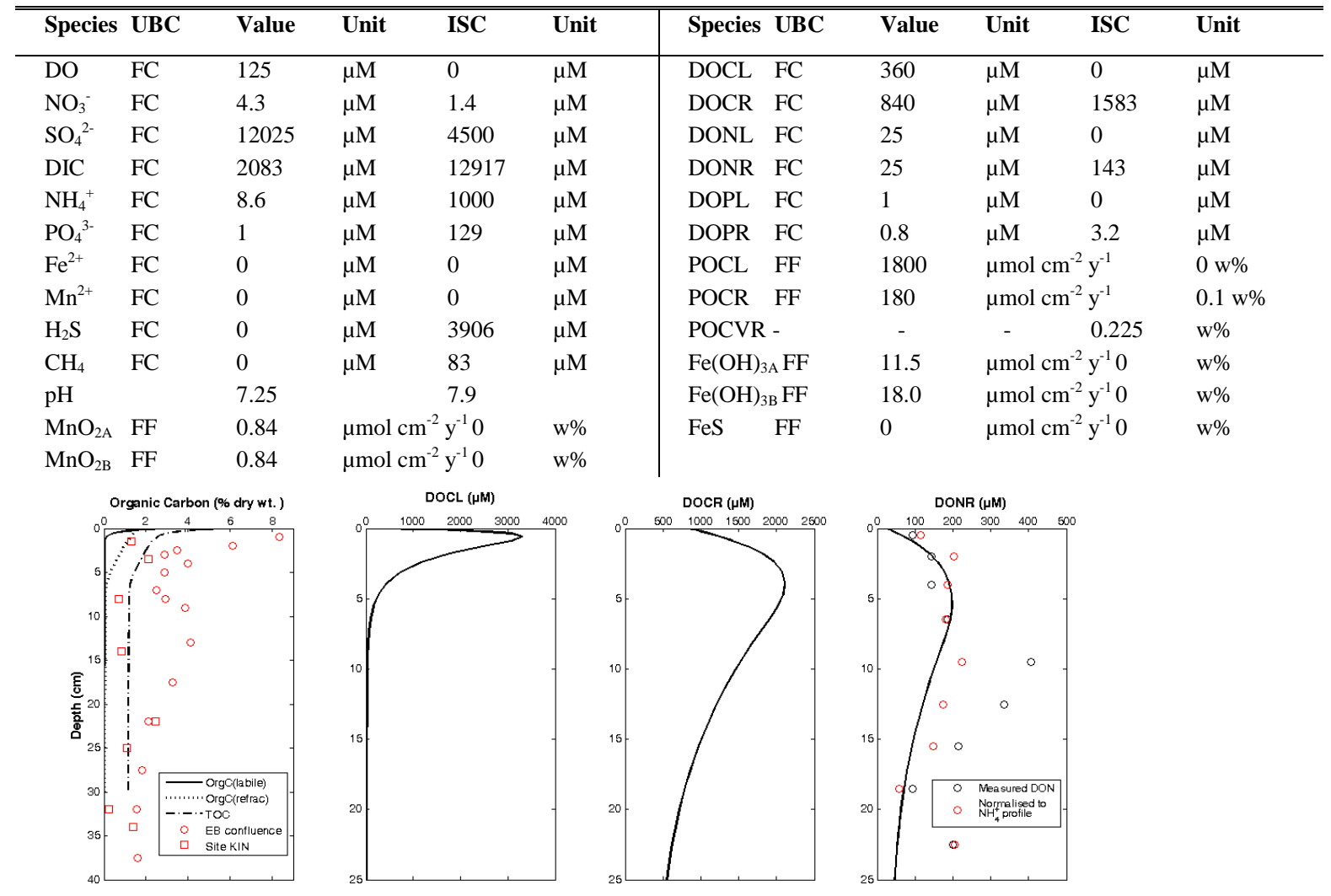



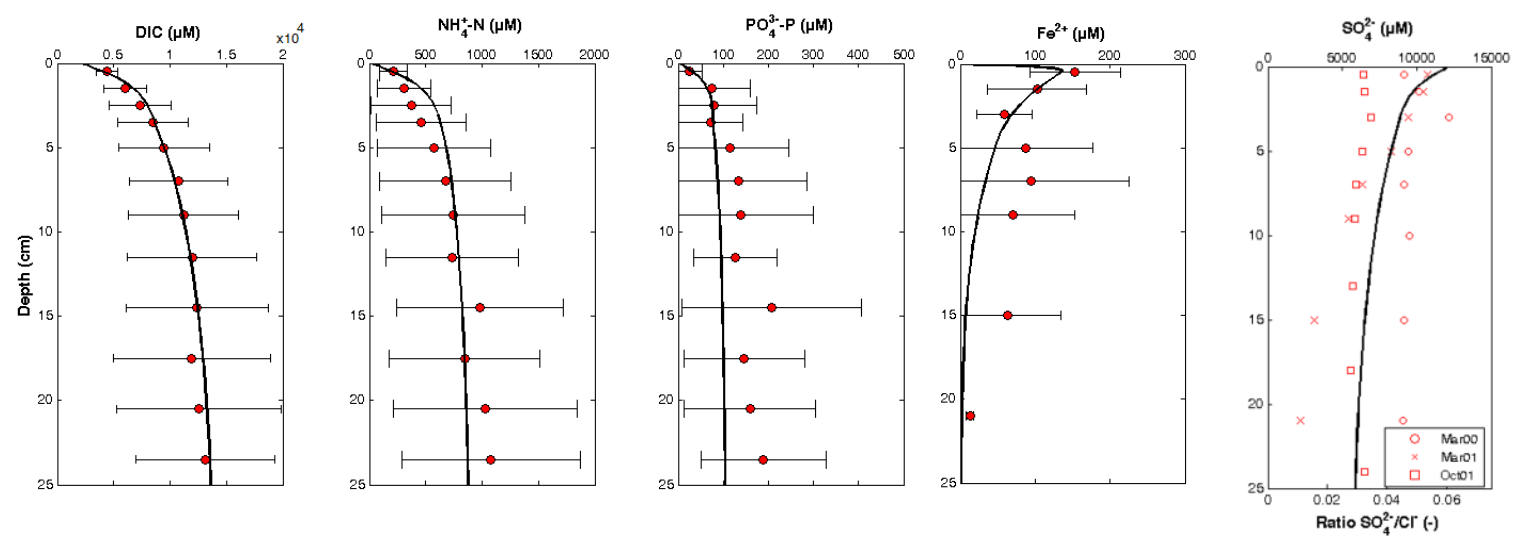

Figure 1 Steady state modelled profiles (solid line) against field data (red closed circles - open symbols indicate useful but not directly comparable data).

\section{OXYGENATION EXPERIMENTS}

Having established the steady-state profile, the model was run dynamically to test two major conditions, with several variations of each: oxygen fluctuation brought about by either natural seasonal variation or operation of the oxygenation plant (Table 3). The oxygen fluctuation was parameterised as a sine oscillation, with a mean of $4 \mathrm{mg} \mathrm{L}^{-1}$ and an amplitude of $4 \mathrm{mg} \mathrm{L}^{-1}$, based on bottom water oxygen data (Figure 2). A relationship was established between bottom water oxygen and fractioning of total $\mathrm{N}$ to describe the seasonal fluctuation, based on water column dissolved oxygen and inorganic nitrogen (DIN) concentrations (Figure 2). For the simulation of the oxygenation plant, a boundary condition of an increase in oxygen concentration to $10 \mathrm{mg} \mathrm{L}^{-}$

${ }^{1}$ was imposed on the seasonal fluctuation. In two different simulations, the increase to $10 \mathrm{mg} \mathrm{L}^{-1}$ was imposed for one day in the first simulation, and for two days in the second, with a day in between during which concentrations returned to the base level from seasonal fluctuation. During the winter period, oxygen concentrations were simulated at above $5 \mathrm{mg} \mathrm{L}^{-1}$, and therefore no pumping was simulated Figure 3.

Table 3 Summary of the simulations run under seasonal oxygen fluctuations or the simulated oxygenation plant

\begin{tabular}{lll}
\hline \hline Oxygen boundary & Experiment & Parameters changed \\
\hline Seasonal oxygen & 1) base scenario & bottom water oxygen \\
fluctuation & 2) salinity fluctuation & $\mathrm{SO}_{4}{ }^{2-}$ and other salt ions \\
& 3) changed nitrification rate & nitrification rate constant \\
& 4) changed bottom water $\mathrm{NO}_{3}{ }^{-}$and $\mathrm{NH}_{4}^{+}$ & average bottom water DIN \\
& concentrations & concentration $+/-25 \%$ \\
& 5) include irrigating benthic fauna & irrigation depth $8 \mathrm{~cm} / 0 \mathrm{~cm}$ \\
\hline Bottom water & 6) base scenario & increment $\left(10 \mathrm{mg} \mathrm{L}^{-1}\right)$ in bottom water \\
oxygenation & & $\begin{array}{l}\text { oxygen every second day } \\
\text { scenario } 6 \text { with increased nitrification } \\
\end{array}$ \\
& 7) changed nitrification rate & rate constant
\end{tabular}
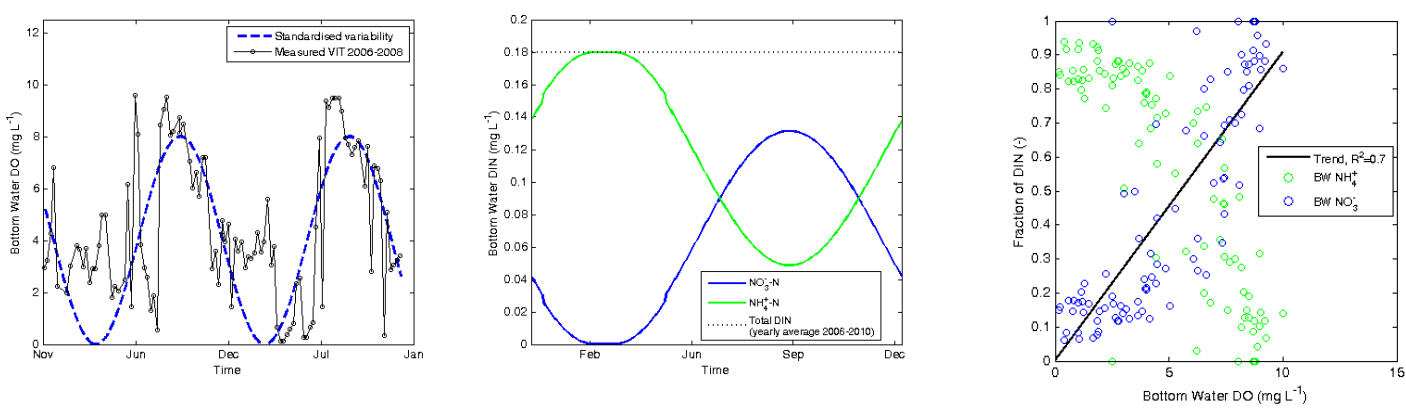

Figure 2 Sine function imposed for oxygen fluctuations, based on Swan River data (left). Total DIN flux separated into $\mathrm{NO}_{3}^{-}$and $\mathrm{NH}_{4}{ }^{+}$(centre) based on the relationship found between oxygen concentration and DIN (right). 


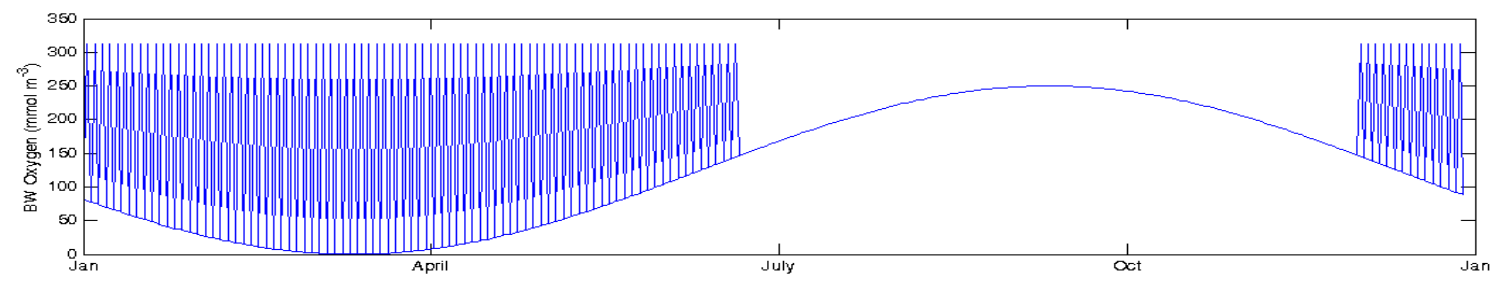

Figure 3 Imposed oxygen boundary with pumping by the oxygenation plant every second day if the oxygen concentration is below $5 \mathrm{mg} \mathrm{L}^{-1}$

\section{RESULTS}

The base scenario of the seasonally fluctuating oxygen concentration showed an oxygen penetration depth that directly followed the concentration in the bottom water i.e. no hysteresis was seen, as might be expected after the period of anoxia (Figure 4). The maximum penetration depth was $1 \mathrm{~mm}$, and occurred when the bottom water oxygen concentration peaked. A fairly constant efflux of $\mathrm{NH}_{4}{ }^{+}$of approximately $16.3 \mathrm{mmol} \mathrm{N}$ $\mathrm{m}^{-2} \mathrm{~d}^{-1}$ was found throughout the year. The slightly deviating maximum and minimum mirrored the prescribed bottom water concentration but was also consistent with an increase and a decrease in the $\mathrm{NH}_{4}{ }^{+}$ concentration in the top sediment when bottom water oxygen concentration went from anoxia to $8 \mathrm{mg} \mathrm{O}_{2} \mathrm{~L}^{-1}$. Based on the average modelled flux of $\mathrm{NH}_{4}{ }^{+}$and the measured average net primary production rate of $1.55 \mathrm{~g}$ $\mathrm{C} \mathrm{m}^{-2} \mathrm{~d}^{-1}$ in the estuary (Thompson 1998) this amount of $\mathrm{NH}_{4}{ }^{+}$alone would be able to sustain $83 \%$ of the primary production, assuming Redfield ratio. The flux of nitrate was into the sediment all year and the magnitude of the flux also followed the prescribed bottom water concentration, with nearly no influx during the period of anoxia and highest influx during high oxygen conditions. The concentration in the sediment was constantly below the half saturation constant of $25 \mu \mathrm{M}$ used for denitrification in the model. The period where the highest influx was modelled is the period with high river flow and increased $\mathrm{NO}_{3}{ }^{-}$concentrations in the water column, and thus the applied constant dissolved inorganic nitrogen (DIN) boundary (around which the fraction of $\mathrm{NH}_{4}{ }^{+}$and $\mathrm{NO}_{3}{ }^{-}$was distributed) has a great impact on the size of the flux. The modelled yearly average flux in the base scenario was $-1.01 \mathrm{mmol} \mathrm{m}^{-2} \mathrm{~d}^{-1}$. A sensitivity test was performed where the constant DIN concentration was increased and decreased by $25 \%$ and showed an almost linear response between the average bottom water DIN concentration and $\mathrm{NO}_{3}{ }^{-}$flux into the sediment, while $\mathrm{NH}_{4}{ }^{+}$fluxes changed less than $0.5 \%$. Assuming the modelled sediment flux represents the average upper estuary $(0.45$ $\mathrm{km}^{2}$ ) these base scenario fluxes correspond to a total yearly nutrient input of 37.5 tonnes of $\mathrm{NH}_{4}{ }^{+}$and -2.3 tonnes $\mathrm{NO}_{3}{ }^{-} . \mathrm{PO}_{4}{ }^{3-}$ flux was also near constant during seasonal fluctuations in the base scenario, with a peak at the end of the season, and a flux $10 \%$ higher than the yearly average of around $0.96 \mathrm{mmol} \mathrm{N} \mathrm{m}^{-2} \mathrm{~d}^{-1}$.
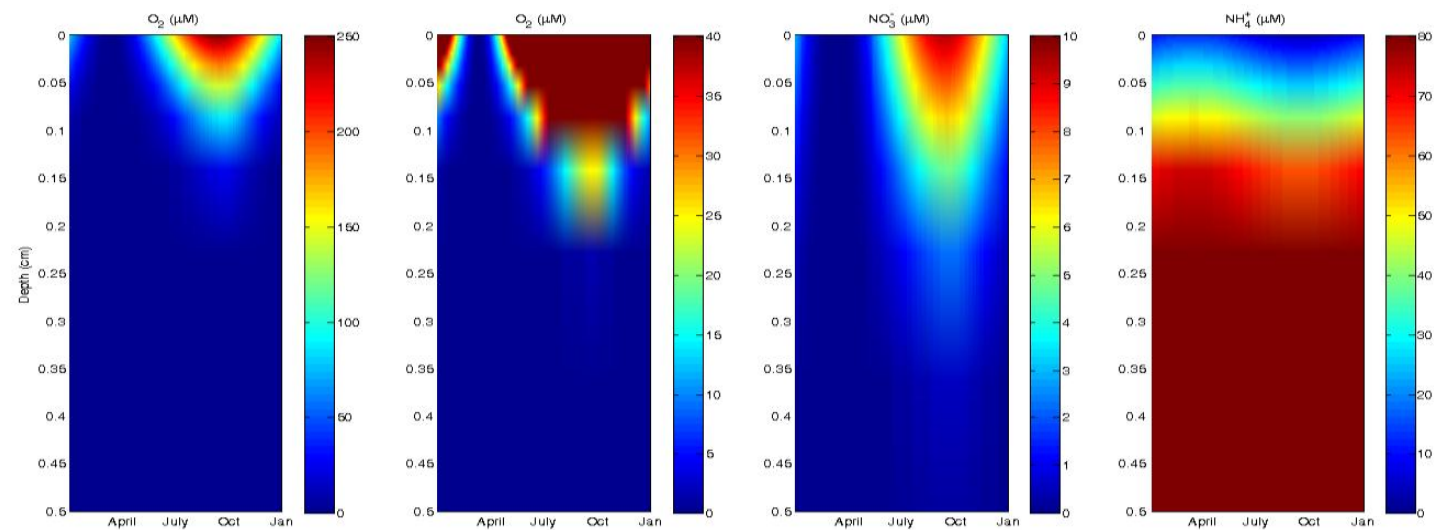

Figure 4 (Left) Simulated oxygen penetration during a seasonal fluctuation. (Centre left) The same oxygen penetration indicated as the depth to the zone where the concentration is more than $40 \mu \mathrm{M}$, corresponding to the Monod constant of oxygen reduction applied in the simulation. (Center right) $\mathrm{NO}_{3}{ }^{-}$concentration in the sediment (Monod constant of $25 \mu \mathrm{M}$ applied in the model). (Right) $\mathrm{NH}_{4}{ }^{+}$concentration in the sediment.

The bottom water oxygenation scenario showed that an increased oxygen concentration resulted in an immediately increased sediment oxygen demand (SOD). The natural oxygen concentration did not greatly affect the SOD and only varied from approximately $97 \mathrm{mmol} \mathrm{m}^{-2} \mathrm{~d}^{-1}$ when oxygenated during the anoxic period to approximately $93 \mathrm{mmol} \mathrm{m} \mathrm{m}^{-1}$ when the bottom water was $5 \mathrm{mg} \mathrm{L}^{-1}$ prior to oxygenation. When oxygenation was switched off, SOD returned to the same level as modelled in the base scenario. The depth to 


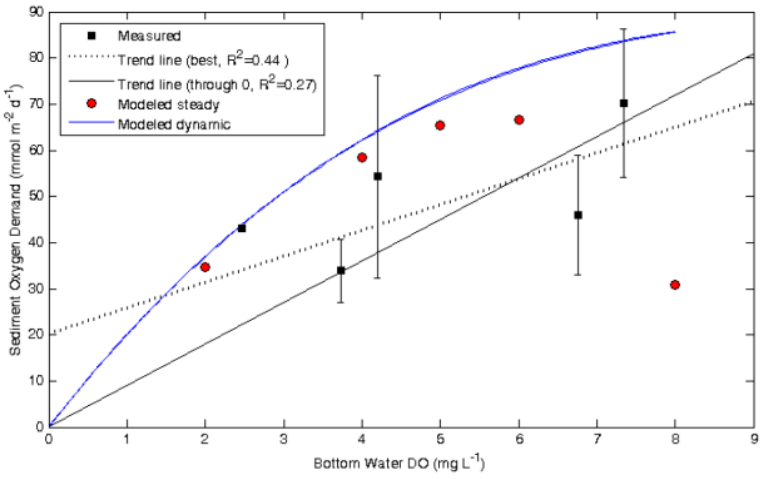

Figure 5 Modelled sediment oxygen demand under different bottom water oxygen conditions. Measured values are given as average $+/-$ one standard deviation. The measured value at $2.3 \mathrm{mg} \mathrm{L-1}$ is not included in the trend lines.

the anoxic zone was slightly affected by the oxygen concentration prior to oxygenation and did not increase from the first to the second day of oxygenation. $40 \mu \mathrm{M}$ was seen to a depth of approximately $1 \mathrm{~mm}$ and from $3 \mathrm{~mm}$ to the anoxic zone there was an oxygen concentration of less than $1 \mu \mathrm{M}$ (Figure 6). A similar penetration depth was seen in the base scenario during the period of high oxygen concentrations, peaking at 8 $\mathrm{mg} \mathrm{L}^{-1}$ (Figure 4). When the bottom water was not oxygenated, the porewater oxygen was immediately consumed (Figure 5Figure 7). The days of oxygenation showed a slightly increased nitrification meaning that efflux of $\mathrm{NH}_{4}^{+}$was reduced and the influx of $\mathrm{NO}_{3}{ }^{-}$either decreased or shifted to a flux out of the sediment.

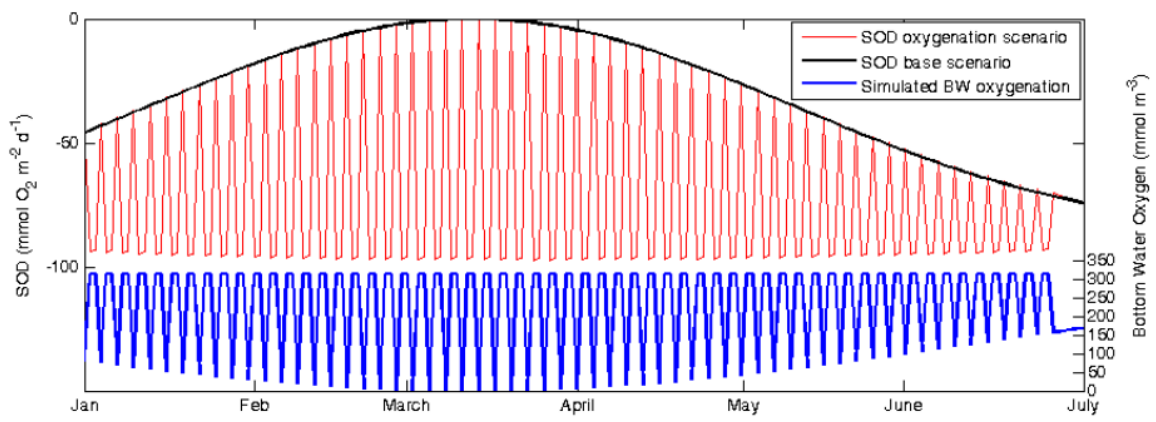

Figure 7 Response of the SOD to bottom water oxygenation.

\section{DISCUSSION}

The oxygenation scenario revealed that the timescale of maximum oxygen penetration was less than that of the fluctuating oxygen concentration of one day since no increment in penetration depth was seen during the two days of oxygenation. This implies the need for further investigation of fluctuations on a shorter timescale, which is currently not possible in this model. This also indicates that the daily fluctuation resulting from the water column respiration overnight could be important in the estimation of the nutrient budget. To evaluate the effect of oxygenating the water, scenarios with a more gradual increase and decrease in oxygen concentration should be set up. Moreover, the demonstrated model sensitivity to water column $\mathrm{NO}_{3}{ }^{-}$ concentration and the denitrification rate indicates that the response in water column nitrification to the oxygenation could be important in this kind of scenario.

A limitation was found in the modelling of different bottom water oxygenation strategies, since no long-term effects of oxygenating the water can be investigated due to the constant degradation rate and the missing feedback between sediment nutrient fluxes and water column dynamics. The sediment response to oxygenating the water was fixed at the base scenario simulation and so the immediate return to the flux modelled in the base scenario when oxygenation was switched off was a result of the organic matter degradation rate being constant throughout the simulation period. The only effects seen in the presented oxygenation scenario were therefore a result of an increased nitrification-denitrification. The choice of the nitrification rate constant is important with respect to the estimated denitrification in the oxygenation 
scenario and also during the seasonal oxygen fluctuation cycle. The choice of $\mathrm{NO}_{3}{ }^{-}$concentration at the upper boundary was also shown to be a sensitive parameter with respect to the modelled denitrification when the in situ production of $\mathrm{NO}_{3}^{-}$from nitrification is low. The denitrification efficiency could be increased by increasing the nitrification rate constant and applying a constant similar to the one previously tested $\left(1 \times 10^{6}\right.$ $\mathrm{mM}^{-1} \mathrm{y}^{-1}$ ) the yearly total DIN flux out of the sediment decreased by $23 \%$ compared to the base scenario.

The current model setup does not allow for reliable simulations with respect to the effects from more benthic invertebrate communities as a result of oxygenation and a general increased oxygen level. In relation to the high sensitivity to irrigation, a part of the problem was attributed the sharp discontinuity occurring when the irrigation is modelled as a step-function. For the same reasons other simple mathematical descriptions such as a depth distribution, linear or an exponential decrease are applied in several other sediment models (Canavan et al. 2006). In terms of potential model improvements it could also be considered whether irrigation should affect $\mathrm{Fe}^{2+}$ and $\mathrm{Mn}^{2+}$ (Fossing et al. 2004) and whether bioturbation actually affects the solute mixing. Fossing et al. (2004) include a mathematical expression correcting for the reduced impact by bioturbation and bioirrigation during and after anoxic events, which certainly applies to the upper Swan estuary in its current ecological state, where the salt wedge movement also has been found to introduce a temporal variability in the abundance of benthic fauna (Douglas and Adeney 2000). This dynamic die-off and migration of new species have been shown to be sensitive parameters in order to model the sediment-water interaction in hypoxic waters (Morse and Eldridge 2007).

The scenarios presented in this study were all run to a quasi-steady state and with a fixed boundary. Thus the scenarios were only evaluated on a seasonal time-scale and no feedback existed between the simulated changes in sediment-water interaction and the water column dynamics, although Luff et al. (2000) have shown that the nutrient fluxes are highly sensitive to the timing and magnitude of organic matter flux to the sediment surface. In the evaluation of prospective restoration initiatives the resulting changes in sedimentwater interactions must therefore be reflected in the upper boundary condition so that a new equilibrium in the seasonal steady-state dynamics on a longer time-scale can be restored. Ultimately, a 3D hydrodynamic ecological water column model can constitute the upper boundary, thereby taking into account the great effect from the dynamic salt wedge on bottom water conditions with both seasonality and climate variability.

\section{REFERENCES}

Boudreau, B. P. 1996. A method-of-lines code for carbon and nutrient diagenesis in aquatic sediments. Computers \& Geosciences 22: 479-496.

Douglas, G. B., and J. A. Adeney. 2000. Diagenetic cycling of trace elements in the bottom sediments of the Swan River Estuary, Western Australia. Applied Geochemistry 15: 551-566.

Eldridge, and Morse. 2000. A diagenetic model for sediment-seagrass interactions. Marine Chemistry 70: 89.

Eldridge, P. M., J. E. Kaldy, and A. B. Burd. 2004. Stress response model for the tropical seagrass Thalassia testudinum: The interactions of light, temperature, sedimentation, and geochemistry. Estuaries 27: 923-937.

Fossing, H., P. Berg, B. Thamdrup, S. Rysgaard, H. Sorensen, and K. Nielsen. 2004. A model set-up for an oxygen and nutrient flux model for Aarhus Bay (Denmark).

Fredericks, D. J., D. W. Palmer, C. S. Smith, and D. Heggie. 2002. Benthic fluxes and nutrient recycling in the Swan Estuary. Geoscience Australia.

Kilminster, K., Z. Goss, S. Evans, G. Evans, M. S. Robb, L. D. Bryant, D. F. Mcginnis, and L. Damgaard. 2011. Artificial oxygenation of the Swan River: assessing sediment condition.

Luff, R., K. Wallmann, S. Grandel, and M. Schluter. 2000. Numerical modeling of benthic processes in the deep Arabian Sea. Deep-sea research. Part 2, Topical studies in oceanography 47: 3039-3072.

Morse, J., and P. Eldridge. 2007. A non-steady state diagenetic model for changes in sediment biogeochemistry in response to seasonally hypoxic/anoxic conditions in the "dead zone" of the Louisiana shelf. Marine Chemistry 106: 239-255.

Smith, Haese, and Evans. 2010. Oxygen demand and nutrient release from sediments in the upper Swan River estuary. Geoscience Australia.

Smith, Murray, Hepplewhite, and Haese. 2006. Sediment Water Interactions in the Swan River Estuary: Findings and Management Implications from Benthic Nutrient Flux Surveys 2000-2006.

Thompson, P. A. 1998. Spatial and temporal patterns of factors influencing phytoplankton in a salt wedge estuary, the Swan River, Western Australia. Estuaries 21: 801-817. 